\title{
Psychosocial Factors Associated with The Hiding of People Living with HIV In the Kenge Health Zone, DRC
} \author{
Kusa $^{2,4}$ and Jules Mapasi Nkunda ${ }^{2,5}$ \\ ${ }^{1}$ Associate Professor, Higher Institute of Medical Techniques Mary Queen of Peace Kenge, RDC \\ ${ }^{2}$ Assistant, Higher Institute of Medical Techniques Marie Queen of Peace Kenge, RDC \\ ${ }^{3}$ Cate veri eur, PBF Program (Performance Based Financing), EUP Kwilu Kikwit antenna, DRC
}

Benjamin Ngongo Mulemba ${ }^{1}$, Orban Mundendi Mafumba*2,3, Rene Madilu Kangulu², Jean Lusambu

${ }^{4}$ Supervisor, Provincial Coordination of Leprosy and Tuberculosis of Kwango, Kenge, DRC

${ }^{5}$ Analyst, Kwango Provincial Health Division, Kenge, DRC

*Corresponding author: Orban Mundendi Mafumba, Assistant, Higher Institute of Medical Techniques Marie Queen of Peace Kenge, RDC

\section{ARTICLE INFO}

Received: 慧 May 06, 2019

Published: 蔧 May 16, 2019

Citation: Benjamin Ngongo M, Orban Mundendi M, Rene Madilu K, Jean Lusambu K, Jules Mapasi N. Psychosocial Factors Associated with The Hiding of People Living with HIV In the Kenge Health Zone, DRC. Biomed J Sci \& Tech Res 18(1)-2019. BJSTR. MS.ID.003102.

Keywords: People Living with HIV (PLHIV); HIV / AIDS; Clandestinity

\author{
ABSTRACT
}

Despite the advances in HIV / AIDS in the last 15 years, the disease continues on its way, though at a slow pace. The purpose of this study is to identify the clandestine life of people with HIV (PLHIV) in the Kenge Health Zone. It was targeted 74 out of the 206 PLHIV supported in 2016-2017. The study used descriptive and inferential statistics to analyze data collected from a questionnaire survey. It reveals the frequencies of the reports according to their profile and the psychosocial factors of their clandestine life. The results indicate that over $50 \%$ of respondents were aged 36 and 45 were female. They were either single (35.2\%), married or living under common-law $(21.6 \%)$. The majority lived in hiding (64.9\%) because of shame (26.1\%), the fear of being rejected (26.1\%), the lack of advice to share their status (21.7\%), fear of stigma (17.4\%), and fear of discrimination (8.7\%). These factors were significantly related to clandestinity because of the age of the respondents $(p=0.0064)$, their attitude towards the non-sharing of their status $(p=0.000)$, their serology $(p=0.0053)$ and the disclosure of the status by a third party $(p=0.00192)$.ss The study concludes that the confidentiality of HIV infection and the clandestine life of its patients are intimately linked because of the magnitude of patients' fear of stigma following the unveiling of their status. However, declaring one's status cannot lead patients to lead a much more responsible life than before contracting HIV / AIDS. A thorough verification of any information about them would be strongly recommended if the reality of their life is known.

\section{Introduction}

According to UNAIDS (2017), are the enormous progress made in the fight against HIV / AIDS over the past 15 years have sparked a global commitment to end the epidemic of 2030. There were in 2016 through the world 36.7 million people living with HIV, of whom 19.5 million (53\%) were on antiretroviral therapy and 1.8 million were newly infected with HIV. Since 2010, new HIV infections among adults have decreased by about $11 \%$ and $47 \%$ in children. AIDS-related deaths have decreased by $48 \%$ since 2005. In 2016, 1 million people died worldwide, compared to 1.9 million in 2005 and 1.5 million in 2010. Currently, 7 0\% of people in the world have died. HIV are informed of their HIV status [1-
3]. The East Africa and Southern Africa are leading the way in the $30 \%$ reduction in the number of new HIV infections since 2010. L e Malawi, Mozambique, Uganda and Zimbabwe have reduced by almost $40 \%$ or more the number of new HIV infections since 2010 [4]. En Republic Démocratique Congo (DRC), the epidemic is generalized decreasing with a prevalence of $1.1 \%$ and $1.2 \%$ in the general population $[5,6]$.

This prevalence was 3.5\% among pregnant women attending ANC in 2011 [5]. It is high in some population groups, especially among prostitutes where it is around $16.9 \%[7,8]$; in the military men $3.8 \%$, among female military personnel $7.5 \%$ to $7.8 \%[7,9]$; 
among truckers $3.3 \%$ and in $2.4 \%$ min i ers. [7]. In the Kwango, the prevalence rate in voluntary testing centers was $0.30 \%$, of which $92 \%$ were on ARVs in 2016 [10]. This prevalence dropped to $0.20 \%$ in 2017 and 1202 cases detected, all 100\% were on ARVs [2]. At present, people living with HIV (PLHIV) should be encouraged to live positively and come forward because of s new hope brought by ARV therapy (ART) and the benefits they their offer. M nfortunately, Kenge in the health area, over $60 \%$ are still in hiding. Our major concern is to answer the following questions: what factors have sociés to Clandesti ne ed of PLHIV in the Z one of H ealth Kenge? What proportion of PLHIV output s of hiding? Is there a relationship between these factors and life in clandestine ity? We think that are the factors associated with clandestine ity PLHIV would be shame, fear of rejection, lack of $d$ es prescribers' advice to get them to share their HIV status, fear of stigma and discrete imination (self-stigma). L proportion of PLHIV declared to be out of hiding would be low in the Kenge Health Zone. he there would a significant $r$ elation between the said factors and clandestine ity.

The general objective of this study is to etermine factors associated with the Clandesti nit s PLHIV. S pecific ment, it comes to the proportion of PLWHA etermine output s of cland estinité; to identify the factors associated with the clandestine era ; to e xplore the relationships between these factors and underground PLHIV. The results This study may serve as a future research topic in this area. L determining factors associated with the illegal ity of PLWHA in the context K wangolais help all stakeholders to develop strategies to encourage PHAs to come out of hiding. The updated information provided by this study will help associations fighting against HIV and community leaders to reframe their messages delivered during the awareness course.

\section{Literature Paper}

With regard to the profile of people living with HIV, the HIV pandemic is a gender issue (ASP Canada 2015 ), marital status (UNESCO 2003) and age, ( Boucher 2014). For p roportion PLHIV out of hiding, UCOP + (2012), reveals that 37.8\% of PLWHA have communicated themselves to their status érologique $s$ aut res people and UNAIDS (2008) indicates that in Tanzania only half of PLHIV reported their HIV status to their partners. The others hesitated because of the psychosocial actors linked to the underground life, the fear of social rejection "or stigma [11-13]. Self- stigmatization by $[14,15]$ fear of rumors in the community, taunts, verbal harassment and loss of friends due to considerations at the beginning of the AIDS epidemic, such as an infection affecting drug addicts, prostitutes and homosexuals [16]. The links between these factors and the underground have been established by the studies of [17], fear of stigmatizing acts ( $p<0.03$ ), self-stigma (UCOP,+ 2012$)$.

\section{Materials and Methods}

\section{Description Milletihad to Study}

The Zone of S Anté (ZS) Kenge is one of the 14 Zones in the Provincial Division of Kwango. It is located in the chief town of
Kwango province. It has 28 health areas. She is limited u North has the ZS Kikongo with the river Wamba; A u south, ZS Kimbau by a full of Makiosi; to the east, the Masi- Manimba ZS by the I nzia River and to the West, the Z S of Boko by the Wamba River. With as a communication channel has the national road No. 1-2 $75 \mathrm{~km}$ from Kinshasa. Its climate is t ropical wet with two seasons: the season of rain, September to May and the dry s eason of May the month of August. Son landscape consists of the s-b avane h erbo idle. With a population of about 2,521,592 inhabitants distributed over a roup s rficie is $89,458 \mathrm{~km} 2$ (so a density of $28 \mathrm{hab}$ / Km 2), of which $20 \%$ of the population vi van $\mathrm{t}$ in art circles urba $\mathrm{n}$ i s and périu rb i ns and $80 \%$ in the art circles rura ux, the Kwango is a province agro-pastoral par excellence [10] . The main companies offering employment are education, health and public administration. Commerce, small and medium enterprise e and s s taxi motorcycles constit uence another source of income.

This health zone is cosmopolitan and contains several ethnic groups among others: Yaka, P elende, Mbala, Suku, and Hungani. The main languages spoken are Kikongo, Lingala, Pelende and Kiyaka. The Pelende ethnic group is the most dominant in the ZS. There are several religions: Catholic, Protestant e, Eg lises clock, Kimbanguiste, Jehovah's Witnesses ... In the field of education, we find: 105 schools and 63 elementary school and several Technical Institute s s Medicales. It has a university ( Kwango University ), a UFL IOR Pedagogical Institute (ISP / Kenge), an Institute S upérieur T echnical M edical (ISTM Mary Queen of Peace Kenge) and some private higher education institutions whose Interdisciplinary Center for Continuing Education (CIDEP), the I $\mathrm{n}$ stitute Superior International Trade (ISIC), the University of $\mathrm{C}$ between professional Management and Development (CEPROMAD). All these higher institutions are in the town of Kenge.

\section{Sampling Methods and Technique Collection of Donations}

The sample in our study is simple random probability. The target audience is 206 PLHIV enlisted in the care service from which a sample 74 PLWHA was fired. To collect the data from the study, the patient survey method was chosen. A closed, closed-ended structured questionnaire served instrument for collecting and recording the information sought. Respondents were interviewed in e $\mathrm{d}$ as he's met at the rendezvous for biological monitoring and taking drugs in health facilities, including the General Hospital of Kenge Reference, the Center of Barrier Health and Medical Center Mgr Jean-Gaspard Mudiso / Dreams.

\section{S Technical Analysis Data}

We made use of descriptive analysis $s$ that emerged as the numbers of respondents ur profile and factor s psychosocial in the form of a frequency table and proportion. Trends were detected based on the following formula:

$$
f=\frac{F o}{F A} * 100[\text { Equation } 1]
$$

Or,

$\mathrm{f}=$ Relative frequency 


\section{FO $=$ Frequency observed \\ $\mathrm{FA}=$ Expected frequency}

The inferential analysis based on test e chi-square (chi ${ }^{2}$ or $\square^{2}$ ) was used to check the links between the underground and PLHIV are psychosocial factors associated with this hiding. This test has vate VERIFY allowed the null hypothesis that there was no relat ion e $n$ tre the expected distribution of s workforce illegal PLHIV (E) and observed that e da ns the distribution are suspected psychosocial factors explained st the e ur hiding (0). Thus, the century following assumptions have been testing e e s:

$\mathrm{SH}_{0:} \mathrm{E} \neq 0$, there is a significant difference ent $\mathrm{r}$ e distributions of $\mathrm{E}$ and $\mathrm{O}$

a) $\mathrm{H}_{1 \mathrm{E}}=0$, There 'a a u cu not significant difference between the distributions of $\mathrm{E}$ and $\mathrm{O}$

From an analytical point of view, the chi-square statistic $\left(\mathrm{Khi}^{2}\right.$ or $\square^{2}$ ) is represented by the following formula (Equation 2):

$$
\chi_{d d l ; p}^{2}=\sum \frac{\left(E_{j}-O_{i}\right)^{2}}{O_{i}}(\text { Equation 2) }
$$

Where,

$E_{i}$, the $i^{\text {th }}$ expected workforce of s PLHIV clandestine

$\mathrm{O}_{j}$, the $\mathrm{j}^{\text {th }}$ observed effective da ns distribution psychosocial factors associated with underground PV HIV

$\mathrm{ddl}$, the degree of freedom (equal to $\mathrm{nk}$ )

$n$, the total number of the sample

$k$, the number of estimated parameters (equal to the number of factors)

$p$, the signi fi cation rate (equal to the probability of failure of Ho)

The chi-square $\left(\mathrm{Khi}^{2}\right)$ statistic was tested at the $5 \%$ significance level ( $\mathrm{p}=0.05$ ) using SPSS 12.0 and MS Excel 2010 computer software.

\section{Analysis of Results}

\section{Profile of Respondents}

The results in Table 1 reveal the profile of the respondents. Compared to the age group, $51.4 \%$ among enquêt e s were between $36-45$ ans followed by $16.2 \%$ between $46-55$ ans, $16-25$ ans $13.5 \%$, $10.8 \%$ of over 56 years old and $8.1 \%$ from $26-35$ years old. In terms of gender, $51.4 \%$ were female compared to $48.6 \%$ male (Table 2 ). With respect to marital status, married and common-law couples accounted for $21.6 \%$ fairly, while single, widowed, divorced and other categories (including mother-daughters) were $35.2 \%, 16.2 \%$, $5.4 \%$ and $10.8 \%$ (Table 3 ).

Table 1: Age distribution.

\begin{tabular}{|c|c|c|}
\hline age (years ) & Frequency & Percentage \\
\hline $16-25$ & 10 & 13,5 \\
\hline $26-35$ & 6 & 8,1 \\
\hline
\end{tabular}

\begin{tabular}{|c|c|c|}
\hline $36-45$ & 38 & 51,4 \\
\hline $46-55$ & 12 & 16,2 \\
\hline 56 and p read & 8 & 10,8 \\
\hline Total & 74 & 100,0 \\
\hline & & \\
\hline
\end{tabular}

Source : Authors (2018)

Table 2: Distribution by gender.

\begin{tabular}{|c|c|c|}
\hline Sex & Frequency & Percentage \\
\hline M & 36 & 48,6 \\
\hline F & 38 & 51,4 \\
\hline Total & 74 & 100,0 \\
\hline
\end{tabular}

Source : Authors (2018)

Table 3: Distribution by marital status.

\begin{tabular}{|c|c|c|}
\hline Marital status & Frequency & Percentage \\
\hline Married (e) & 16 & 21,6 \\
\hline Single & 26 & 35,2 \\
\hline Widower (Ve) & 12 & 16,2 \\
\hline Divorced (e) & 4 & 5,4 \\
\hline Free Union & 16 & 21,6 \\
\hline Total & 74 & 100,0 \\
\hline
\end{tabular}

Source : Authors (2018)

\section{Proportion of PLHIV Exited from Hiding}

Compared to life in hiding, Table 4 indicates that $64.9 \%$ are those who live in hiding compared to $35.1 \%$ of those who have disclosed their serological status. 4.3 Psychosocial factors related to the illegality of PLHIV Regarding the perception in relation to their status e sérologi that the announcement of the results, $62.2 \%$ of patients surveyed believe HIV like any other disease ; $18.9 \%$ consider it a divine punishment ; $16.2 \%$ attributed it to witchcraft and $2.7 \%$ perceived it as a curse (Table 5) .Asked about the reasons for not sharing their status, $26.1 \%$ cited shame and fear of being rejected as obstacles to the announcement of their status, onitoring s s $21.7 \%$ since $n$ ' were never advised es of reveal their status to others. Some were afraid to face stigma (17.4\%) and a u t r es, discrimination (8.7\%) (Table 6 here below).

Table 4: E nquêtés having dévoil é status sérologi that e.

\begin{tabular}{|c|c|c|}
\hline Unveiling of his serology & Frequency & Percentage \\
\hline O ui & 26 & 35,1 \\
\hline No & 48 & 64,9 \\
\hline Total & 74 & 100,0 \\
\hline
\end{tabular}

Source : Auteurs (2018)

Table 5: Perceptions of their status as sérologi after diagnosis

\begin{tabular}{|c|c|c|}
\hline Attitude Towards His Serology & Frequency & Percentage \\
\hline Witchcraft & 12 & 16,2 \\
\hline Divine punishment & 14 & 18,9 \\
\hline Diseases like others & 46 & 62,2 \\
\hline Curse & 2 & 2,7 \\
\hline Total & 74 & 100,0 \\
\hline
\end{tabular}


Source : Authors (2018)

Table 6: Reasons to stay in hiding.

\begin{tabular}{|c|c|c|}
\hline Reason & Frequency & Percentage \\
\hline S stigmatisation & 8 & 16,6 \\
\hline D discrimination & 4 & 8,3 \\
\hline R éjecté social & 12 & 25 \\
\hline H onte & 12 & 25 \\
\hline Consulting missing prestat has ries & 10 & 20,8 \\
\hline Refusal to share & 2 & 4,1 \\
\hline Total & 48 & 100 \\
\hline
\end{tabular}

Source : Authors (2018)

\section{Relationships Between Psychosocial Factors and Clandestinity of PLHIV}

Relationships Between Patient Profiles And A Clandestine Life Of PLWHA: After testing the relationships between different factors and hiding, confirmed by the chi-square test, the patient's age $\left(\mathrm{chi}^{2}=19.43\right.$ dof $\left.=4, \mathrm{P}=0.00640\right)$ was positively and significantly associated people living with HIV go underground in Kenge Health Zone (Table 7)

Table 7: Relationship between age and the hiding of PLHIV

\begin{tabular}{|c|c|c|c|c|}
\hline \multirow{3}{*}{ Age (years) } & \multicolumn{4}{|c|}{ Sharing the serological status } \\
\hline & \multicolumn{2}{|c|}{ Yes } & \multicolumn{2}{|c|}{ No } \\
\hline & $\mathbf{N}$ & $\%$ & $\mathbf{N}$ & $\%$ \\
\hline $16-25$ & 4 & 15.4 & 6 & 12.5 \\
\hline $26-35$ & 0 & 0 & 6 & 12.5 \\
\hline $36-45$ & 10 & 38.4 & 28 & 58.3 \\
\hline $46-55$ & 4 & 15.4 & 8 & 16.7 \\
\hline 56 et plus & 8 & 30.8 & 0 & 0 \\
\hline Total & 26 & 100 & 48 & 100 \\
\hline
\end{tabular}

Source : Authors (2018)

\section{Relations Between F Psychosocial Actors and The Illegality}

The results in Table 8 show that the hiding of PLHIV is related to their perception of their HIV status. Considering the disease as a divine punishment, curse, or witchcraft reinforces patients to remain in hiding. $\left(\mathrm{Chi}^{2}=12.697696, \mathrm{dd} 1=3.0, \mathrm{P}=0.0053\right)$.

Table 8: Relationship between the perception of HIV status and clandestinit é.

\begin{tabular}{|c|c|c|c|c|}
\hline \multirow{2}{*}{ Perception } & \multicolumn{4}{|c|}{ Sharing the serological status } \\
\cline { 2 - 5 } & \multicolumn{3}{|c|}{ Yes } & \multicolumn{2}{c|}{ No } \\
\cline { 2 - 5 } & Not & $\%$ & Not & $\%$ \\
\hline Witchcraft & 4 & 15 & 8 & 17 \\
\hline Divine punishment & 0 & 0 & 14 & 29 \\
\hline Diseases like others & 20 & 77 & 26 & 54 \\
\hline Curse & 2 & 8 & 0 & 0 \\
\hline Total & 26 & 100 & 48 & 100 \\
\hline
\end{tabular}

Source Authors (2018)
Regarding the reasons for staying in hiding $\left(\mathrm{Khi}^{2}=65.85\right.$, dof $=$ $5.0, \mathrm{P}=0.000$ ), Table 9 demonstrates that stigma, discrimination, social rejection, shame and lack providers are associated with clandestinity (Table 9).

Table 9: Relationship between the reasons and the illegal ity of PLHIV é 1.

\begin{tabular}{|c|c|c|c|c|}
\hline \multirow{2}{*}{$\begin{array}{c}\text { The Reasons For Not } \\
\text { Sharing }\end{array}$} & \multicolumn{3}{|c|}{ Sharing the serological status } \\
\cline { 2 - 5 } & Not & $\%$ & \multicolumn{3}{c|}{ No } & $\%$ \\
\cline { 2 - 5 } & 0 & 0 & 8 & 17 \\
\hline stigmatization & 0 & 0 & 4 & 8 \\
\hline Discrimination & 0 & 0 & 12 & 25 \\
\hline Social rejection & 0 & 0 & 12 & 25 \\
\hline Shame & 0 & 0 & 10 & 21 \\
\hline Lack of advice & 26 & 100 & 2 & 4 \\
\hline Refusal to share & 26 & 100 & 48 & 100 \\
\hline Total & & & &
\end{tabular}

Source : Authors (2018)

Note : Significant variable at $1 \%$ significance level $(\mathrm{Kh} 2=65,858$ $; \mathrm{ddl}=5 ; \mathrm{p}=0.000$ )

\section{Discussion of Results}

\section{Profile of People Living With HIV}

The profile of respondents confirms that sexually active people are most concerned with the transmission of HIV infection. In DR Congo, sexual transmission accounts for $80 \%$ of cases, and is aggravated by e OTH ER risk contract of ion're STIs, if not None Average protective measure is pr ise account (NAP 2011). This evolution of HIV infection tends No. No only to spread but also have negative effects of art on demography and family imbalances, mostly explained by the widow's rate. The s $16.2 \% \mathrm{nt}$ clearly shows that there has been death of a spouse. Added to this is the phenomenon of divorce. UNAIDS (2006), even think that the sharp rise in AIDS deaths has interrupted or erased life expectancy gains in many African countries.

\section{Proportion of PLHIV Out of Hiding}

The proportions of the PHAs disclosed their HIV status were lower century to girls as UNAIDS (2009) found e s Tanzania. Only half of PLHIV shared their HIV status with their partners. This undisclosed strategy was explained by Attaher (2005) [18]. Silence is a way for people to temporarily escape stigma and discrimination. But it has a serious consequence and can promote a spread of infection within the general population.

\section{Psychosocial Factors Related to The Clandestine Life Of PLHIV}

Reasons that PLHIV do not share their HIV status and to remain in the shadows do not deviate from the question of self-stigma found by UCOP + (2012), Samson (2006) and Kayo (2015) [19]. It is true that the announcement of the positive result is accompanied by serious reactions of internal guilt, the fear of an impending death, 
the fear of negative reactions surrounding the social environment. Good psychosocial supportand the adoption of positive living enable PLHIV to adapt to their illness and consider it a chronic illness. Our argument is supported by the NAP (2011) and Doctors Without Borders (2008), who think that the accompanying person must issue to all information necessary to enable it to understand and know his illness, of appropriating his serological status and value their abilities or skills, in order to implement coping strategies for their illness, to accept their serological status to lead a positive life.

\section{Relationships Between Psychosocial Factors and Hiding}

The links between clandestinity and its motivating factors were donated by Karene (2008), (Loukid 2014), Schaay (2008) and UCOP + (2012) [20-23]. The results of Karène (2008), con t firmen fa i t e that the infection status of the child and the parent is not usually revealed to the extended family. However, studies by Loukid et al. (2014), Schaay (2008) and UCOP + (2012) [24-26] indicate that the clandestinity is significantly related to the fear of stigmatizing acts and self-stigma.

\section{Conclusion}

The HIV is a pandemic that has become a real problem rapidly $s$ ante public and development. Treatments antiretroviral managed to re fai down the number of new infections, reduce the number of AIDS deaths and extend the life of those infected. The trends are being reversed are in the general population with an estimated prevalence is currently $1.1 \%$ in the DRC; nothings least c e e n core rate remains too high in some specific groups such as homosexuals, drug users inje CTABLE to name a few. unfortunately, one finds that many of between c e s personalize're still in hiding in Kenge health zone. The Results of this study have established a Corrétion between underground e $\mathrm{t}$ e profile respondents (age) as well as certain factors psychosocial issues such as stigma, discrimination, social rejection, shame and lack of counseling.

\section{References}

1. (2017) UNAIDS, United Nations Program against AIDS. Backgrounder: World AIDS Day 2017.

2. (2008) UNAIDS, United Nations Program against AIDS. Fight stigma and HIV-related discrimination-an essential element of national AIDS programs. Geneva Switzerland.

3. (2012) UCOP+ Index of stigma and discrimination of people living with HIV. Investigation report. Kinshasa: Democratic Republic of Congo.

4. (2017) ONUSIDA NACP National Program against AIDS and the United Nations Program for the Fight against AIDS. HIV / AIDS figures. Kinshasa: D émocratique Republic of Congo.

5. (2014) PNMLS, Multisectoral National Program for AIDS Control. National Strategic Plan for the fight against HIV and AIDS 2014-2017. Kinshasa: Democratic Republic of Congo.

6. (2014) DRC, Democratic Republic of Congo. Demographic and Health Survey-DRC II, 2013-2014. Kinshasa: Democratic Republic of Congo.
7. (2009) PNMLS, Multisectoral National Program for AIDS Control. National Strategic Plan for the fight against HIV and AIDS, 2010 - 2014. Kinshasa: Democratic Republic of Congo.

8. (2010) UNDP, United Nations Development Program. Gender and HIV in the Democratic Republic of Congo. Kinshasa, Analysis and Guidance Note (December 2010).

9. (2011) PNLS. Epidemiological surveillance report of HIV / AIDS among pregnant women attending ANC services. Kinshasa: D émocratique Republic of Congo.

10.(2018) DPS / Kwango. Health Projection 2018. Kenge: Provincial Directorate of Kwango, Kwango Province, Democratic Republic of Congo.

11. Samson A (2006) Volunteer Engagement of People Living with HIV / AIDS or a Major Chronic Disease: Issues and Challenges, Research Report. Ottawa ON: University of Ottawa Canada.

12. Schaay N (2008) Stigma Index of People Living with HIV: User's Guide. London: International Planned Parenthood Federation.

13. Moha, M (2011) Even the food, you get tired of eating it. PLHIV and drugs in Niger. Studies and Works n ${ }^{\circ} 94$ (November 2011).

14. Nzie A (2010) Factors associated with attitudes of stigmatization towards people living with HIV / AIDS in Cameroon. Yaound é: Republic of Cameroon.

15. Kayo, JC (2015) The consequences of self-stigmatization.

16. Makano A (2007) Care for People Living with HIV / AIDS in Butembo City, Ruwenzori Official University, Faculty of Social, Political and Administrative Sciences, Democratic Republic of Congo.

17. Loukid M (2014) Question of sharing the HIV status of people living with HIV in Morocco. Casablanca: Kingdom of Morocco.

18. Attaher 0 (2005). Stigma and discrimination practices associated with HIV / AIDS in Mali, presented as a partial requirement of the MA in Sociology. Montreal: University of Quebec in Montreal Canada.

19. (2017) FIU, French Red Cross. 2017 Annual Report. HIV-New Funding Model Project-Sanru Global Fund, Kwango cluster. Kinshasa: Democratic Republic of Congo.

20. (2008) MSF, Médecins Sans Frontières. Accompanying the child patient infected with HIV. Paris: Médecins Sans Frontières (MSF), French Republic.

21. (2006) UNAIDS, United Nations Program against AIDS. Report on the Global AIDS Epidemic, Geneva, 2006.

22. (2011) PNLS, National AIDS Program. Integrated Module of Providers in HIV / AIDS, Kinshasa, Democratic Republic of Congo.

23. Proulx-Boucher K (2008) Biographical Forks: the unveiling of the diagnosis from the point of view of HIV-infected adolescents in the perinatal period, Université du Québec à Montréal. Montreal, Canada.

24. Traore Niélé (2013) Qualitative study of the decision-making of women living with HIV about the disclosure or not of their seropositivity in Bamako, University of Sciences, Techniques and Technologies of Bamako, Mali.

25. (2003) UNESCO, United Nations Educational, Scientific and Cultural Organization. The cultural approach to HIV / AIDS prevention and treatment. Act of the round table organized on November 29, 2002. Paris: UNESCO Secretariat, Republic French.

26. (2016) Administrative Census 2016. Kenge: Town Hall of Kenge City, Kwango Province, Democratic Republic of Congo. 


\section{ISSN: 2574-1241}

DOI: 10.26717/BJSTR.2019.18.003102

Orban Mundendi M. Biomed J Sci \& Tech Res

(c) (i) This work is licensed under Creative

Submission Link: https://biomedres.us/submit-manuscript.php

$\begin{array}{ll}\text { BIOMEDICAL } & \text { Assets of Publishing with us } \\ \text { RESEARCHES } & \text { - Global archiving of articles } \\ \text { - Immediate, unrestricted online access } \\ \text { - Rigorous Peer Review Process }\end{array}$

